\title{
Treatment Planning for Paediatric Exodontia under General Anaesthesia: A Re-Audit
}

\section{Iffah Zaman*}

Northwick Park Hospital, London North West Healthcare, NHS Trust, UK

${ }^{\star}$ Corresponding author: Iffah Zaman, Northwick Park Hospital, London North West Healthcare, NHS Trust, UK; E-mail: iffah.zaman@nhs.net

Received: September 16, 2021; Accepted: September 27, 2021; Published: October 01, 2021

\author{
Abstract \\ - The justification for GA \\ - Attendance at a dedicated POA \\ - Pre-operative radiographs and their justification \\ - Pre-operative restorations \\ - Were patients caries free following GA? \\ - Were guidelines adhered to when extracting FPM's including orthodontic considerations? \\ - Were first permanent molars balanced/compensated where appropriate? \\ - Were all poor prognosis deciduous teeth extracted under GA? \\ - Was appropriate consideration given to balancing/compensating extractions? \\ - Record keeping standards \\ - Were patients appropriately discharged/reviewed?
}

This re-audit of paediatric exodontia under general anaesthetic assessed seventy one patients' GA records across three boroughs in the directorate Bury, Oldham and Rochdale between 02/01/2020 to 17/03/2020. It assessed compliance with Pennine Care local guidelines including:

Results were varied and showed good compliance with some parts of the guidelines such as 70/71 (98.6\%) patients having dedicated POA in the re-audit. The percentage of patients with a dedicated oral health appointment rose from $13.9 \%$ (11/79) for Cycle 1 to $38.0 \%$ (27/71) for Cycle 2 which is a $24.1 \%$ improvement.

The percentage of patients without documented justification for a lack of radiographs dropped from 26.5\% (9/34) for Cycle 1 to $9.1 \%$ (3/33) for Cycle 2 . This shows a $17.4 \%$ improvement.

There were improvements in the numbers of patients having appropriate balancing extractions for unilaterally carious deciduous canines: 6/9 (66.7\%) for Cycle 1 and 11/13 (84.6\%) for Cycle 2. This shows an improvement of 17.9\%

24/26 of patients (92.3\%) in Cycle 2 who had planned extraction of FPM's had pre-operative x-rays and there were some improvements in the number of patients with documented orthodontic considerations compared to Cycle 1. For example:

The number of patients with documented assessment of crowding rose from 16.7\% (4/24) in Cycle 1 to $85.2 \%$ (23/27) in Cycle 2. This is a $71.8 \%$ improvement.

The percentage of patients who were advised of the risk of future mesial tipping or malocclusion of the second permanent molars rose from $8.3 \%$ (2/24) in $\mathrm{C} 1$ to $57.7 \%(15 / 26)$ in C2. This is a $49.4 \%$ improvement.

$94.3 \%$ (67/71) of patients were caries free following completion of GA in the re-audit whereas the target is $100 \%$. However, some of these findings appear to be record keeping errors.

Greater consistency is needed regarding record keeping as well as the post-operative review/discharge process. A greater awareness of the guidelines would be helpful. 


\section{Introduction}

The prevalence of dental decay amongst children is high in England and especially so in the North West.

The Community Dental Services under Pennine Care NHS Foundation Trust (now Bridgewater Community Healthcare NHS Foundation Trust) receive a high number of referrals for paediatric exodontia each year. This treatment under GA is not only costly, but there are ever increasing waiting lists [1-4].

\section{Aim/Objectives}

\section{Aims}

This re-audit retrospectively evaluated the pre-operative planning process for Paediatric exodontia under GA and the post-operative outcomes against Pennine Care local guidelines.

\section{Objectives}

- Evaluate current practice for treatment planning paediatric patients for exodontia under general anaesthesia and compare this to local guidelines.

- Determine whether the treatment carried out under GA followed the pre-operative treatment plan.

- Identify improvements that have been made since the previous audit, and define further areas for change.

\section{Criteria and Standards}

The guidelines measured in this Audit are based on local guidelines published on Pennine Care Trust Intranet. These local guidelines were in turn drawn from published national guidelines from the Royal College of Surgeons, British Society of Paediatric Dentistry and a consultant opinion group from the Community Dental Service Section of the BDA. The local guidelines are included in the appendix section of this proposal; these guidelines were published in 2016.

For simplicity and the purpose of this audit we assessed compliance with the local guidelines using the following summarised points:

1. Was there clear justification for extractions under GA?

2. Did patients attend a dedicated pre-operative assessment?

3. Were appropriate radiographs taken and justified if not taken?

4. Were restorations carried out on teeth prior to GA if to be retained?

5. Were all poor prognosis deciduous teeth planned for extraction?

6. Was consideration given to deciduous balancing/ compensating extractions? E.g. balancing canines to avoid centre line shift or balancing primary first molars in the absence of spacing?

7. Was a diagnostic OPG x-ray taken for FPM extraction?

8. Was an orthodontic assessment carried out for FPM extraction?
9. Was the patient referred for an orthodontic opinion if indicated? E.g. cases with hypodontia, marked skeletal discrepancy and labial/buccal segment crowding

10. Were poor prognosis FPM's extracted at the optimum time?

11. Was the risk of tipping of the second permanent molars discussed where FPM's were planned for extraction?

12. Were FPM's balanced/compensated?

13. Did the treatment plan at the pre-operative assessment match the treatment carried out at GA?

14. Was the patient free of decay following completion of the GA?

15. Were patients appropriately discharged following GA and/or reviewed appropriately?

\section{Standards}

1. All patients should have a dedicated pre-operative assessment prior to the GA appointment and there should be justification for GA documented in the notes.

2. If radiographs are not taken pre-operatively for deciduous extractions, there should be documented justification for this in all cases in the clinical notes.

3. Should a deciduous carious canine require extraction, balancing extraction of the contralateral deciduous canine should be discussed with parents/guardian for preservation of the centre line.

4. Diagnostic OPG should be carried out for all patients undergoing:

a. Timed elective extractions of poor prognosis first permanent molars to encourage mesial drift of the second permanent molar.

b. Balancing/compensative extractions of first permanent molars.

5. An assessment of incisal classification and crowding should be carried out for all patients undergoing elective timed extractions of PFM's and balancing/compensative extractions of PFM's to determine whether orthodontic referral is appropriate.

6. Restorations should be completed for any carious teeth that are planned for retention by the end of the GA session.

7. All paediatric patients should be caries free by the completion of the GA session.

\section{Methodology}

\section{Population}

This re-audit assessed patients' records across three boroughs in the Dental Directorate: Bury Oldham and Rochdale boroughs.

The patients had their dental procedures at either Royal Bolton Hospital or Alder Hey Children's Hospital under General Anaesthesia. 
Inclusion criteria: Paediatric patients (under 16 years) both routine and special care requiring exodontia under GA.

Exclusion criteria: any patients over the age of 16 and patients who do not require GA.

\section{Sample Size/Sampling}

This audit included an anonymised sample of patients from each of our different boroughs and only included patients for routine exodontia under GA treated at either hospital.

Cycle 1 assessed 79 records with GA dates ranging from $01 / 06 / 2017$ to $28 / 07 / 2017$.

Cycle 2 assessed 71 patients with GA dates ranging from $02 / 01 / 2020$ to $17 / 03 / 2020$

\section{Data Collection}

Data was collected retrospectively by I Zaman from the R4 computerised dental clinical records system and the operation notes from the GA appointments which are uploaded onto the R4 software.

A copy of the data collection spreadsheet is included in the appendix.

From this data, we intended to determine the following:

1. Was there general uniformity in the treatment planning for GA exodontia across the different Boroughs in the Directorate?

2. Were the treatment plans from the pre-operative assessment in line with the local guidelines?

3. Was there any discrepancy between the treatment prescribed and the treatment carried out under GA and does this conform to standards?

4. Is there need for further training/development to consolidate treatment planning for paediatric exodontia under GA and to promote greater compliance with guidance across the Directorate?

\section{Data Analysis}

The data was analysed on an Excel spreadsheet by I Zaman.

\section{Data Validity}

A sizeable sample of 71 patients was analysed for this audit which is comparable to the first cycle and also helped to ensure validity and consistency of data collection and analysis.

\section{Results}

\section{Patient Demographics and Pre-operative Assessments}

- $\quad$ Sample $=71$ patients

- The average age of patients was 7.1 years

- 39 patients were male, 32 were female

- The sample included 9 special care patients

- $98.6 \%(70 / 71)$ of patients had a dedicated pre-operative assessment (POA). One patients POA was combined with their dental check-up.

- $38.0 \%(27 / 71)$ of patients had a dedicated oral health appointment.

\section{Justification for Treatment under GA}

The justification for GA at the pre-operative assessment is displayed in Figure 1 below. Multi-quadrant decay was the most frequent justification and three patients had no justification documented. The "other" justifications documented were for 2 patients were "repeated pain" and "decayed teeth".

\section{Pre-operative Radiographs}

Figure 2 below shows the distribution of pre-operative radiographs for patients having deciduous tooth extractions (Table 1).

For two patients the notes stated that $\mathrm{x}$-rays were not needed. However, not all the deciduous molars were clinically carious or planned for extraction. Therefore this was not a valid justification.

\section{Patients Undergoing Extraction of Permanent Teeth}

2 patients mentioned in Table 2 below were originally planned for primary extractions only but ended up undergoing extraction of permanent molars at GA as they were found to be carious. These 2 patients had no pre-operative radiographs as the permanent molars were added to the plan at GA where there was no $\mathrm{x}$-ray facility for routine exodontia. $100 \%$ of patients otherwise had pre-operative radiographs. The distribution of radiographs taken is displayed in Table 2 below (Figure 3 ).

\title{
Justification for GA
}

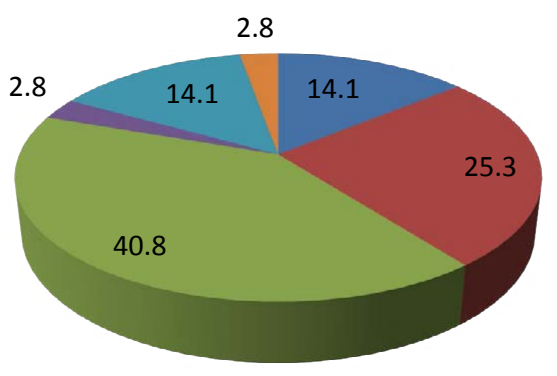

\author{
- Pre-compliant due to age \\ Failed treatment under LA/IHS \\ Multiquadrant decay/number of \\ extractions \\ - No justification \\ Lack of co-operation \\ Other
}

Figure 1: Justifications for GA as percentages. 


\section{Balancing Extractions of Deciduous Canines}

13 patients presented with unilateral decay in a deciduous canine, and balancing extraction was carried out in 11 of these cases. Distribution is displayed in Table 3 below

\section{Balancing Extractions of First Primary Molars}

For this re-audit an additional parameter was added. It assessed if unilaterally carious first primary molars (D's) were balanced in the absence of spacing as per Royal College of Surgeons guidelines ${ }^{3}$.

\section{Pre-operative radiographs for deciduous extractions}

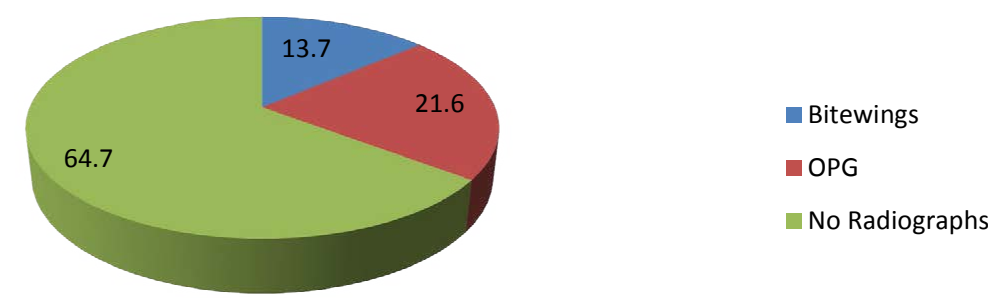

Figure 2: The distribution of pre-operative radiographs for patients having deciduous tooth extractions.

Table 1: Justifications for unavailability of pre-operative radiographs for patients undergoing deciduous extractions.

\begin{tabular}{|l|c|}
\hline Lack of radiographs deciduous extractions - justifications & No. of patients \\
\hline Lack of co-operation & $16(48.5 \%)$ \\
\hline Attempted - patient could not tolerate & $3(9.1 \%)$ \\
\hline All deciduous molars clinically carious & $11(33.3 \%)$ \\
\hline No documented justification for not taking x-rays & $3(9.1 \%)$ \\
\hline Total number of patients & 33 \\
\hline
\end{tabular}

Table 2: Distribution of radiographs taken for patients undergoing permanent dental extractions.

\begin{tabular}{|l|c|}
\hline Radiographs for permanent extractions & No. of patients \\
\hline OPG & $23(88.5 \%)$ \\
\hline Per-apical & $1(3.8 \%)$ \\
\hline Bitewing & $8(30.8 \%)$ \\
\hline No Radiographs due to unexpected change in GA plan & $2(7.7 \%)$ \\
\hline Total number of patients & 26 \\
\hline
\end{tabular}

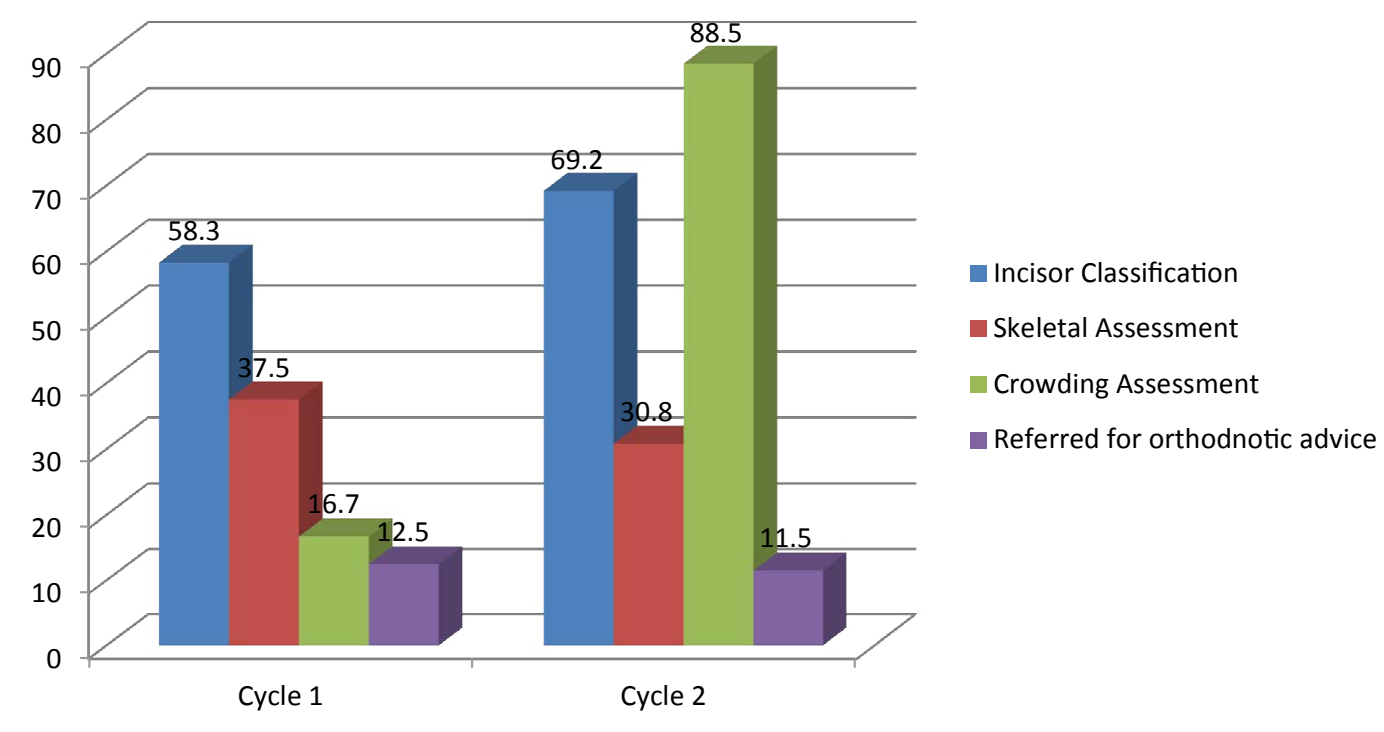

Figure 3: The pre-operative orthodontic assessments that were done before GA. 
$1 / 14$ patients with unilateral decay of a " $D$ " had documented assessment of spacing and was spared a balancing extraction (Table 4).

\section{Extraction of Poor Prognosis First Permanent Molars (FPM)}

- 26/71 patients in this audit underwent extraction of one or more poor prognosis FPM's.

- 12 of these patients underwent planned/timed extraction of FPM's to encourage the mesial migration of the second permanent molar for space closure.

- $23 / 26(88.5 \%)$ had a pre-operative OPG to assess dental development. 2 patients had their permanent molars added to the extraction plan at GA where there is no intra-operative $\mathrm{x}$-ray facility.

- The percentage of patients who had the future risk of 7's tipping mesially or future risk of malocclusion discussed rose from 8.3\% (2/24) in Cycle 1 to 57.7\% (15/26) in Cycle 2.
- A noticeable improvement can be seen especially in the percentage of patients having a crowding assessment. However, the percentage of patients with a skeletal assessment decreased.

\section{Restoration of Teeth}

- 1 special care patient had planned restoration of first permanent molars during GA in this audit.

- 7/71 patients had enough compliance for permanent restorations prior to GA.

- The remaining 63/71 patients in this audit were planned for extraction of all decayed teeth.

\section{Differences between Initial Exam and GA Pre-operative Assessment}

- Figure 4 below shows the differences between the initial exam and POA:

Table 3: Distribution of balancing extractions carried out on deciduous canines.

\begin{tabular}{|l|c|}
\hline Deciduous canine balancing extractions & No. of patients \\
\hline Planned balancing extractions of C's & $11(84.6 \%)$ \\
\hline Balancing extractions discussed - declined by parents & 0 \\
\hline Balancing extractions not carried out - no documentation on justification & $2(15.4 \%)$ \\
\hline Total number of patients with unilateral decay in deciduous canine & 13 \\
\hline
\end{tabular}

Table 4: Distribution of balancing extractions carried out for first primary molars.

\begin{tabular}{|l|c|}
\hline First primary molars balancing extractions & No. of patients \\
\hline Spacing assessment carried out & $1(7.1 \%)$ \\
\hline Balancing extractions discussed - declined by parents & 0 \\
\hline Balancing extractions carried out & 0 \\
\hline Balancing extractions not carried out - no documentation on justification & $13(92.9 \%)$ \\
\hline Total number of patients with unilateral decay in first primary molar & 14 \\
\hline
\end{tabular}

Difference between initial exam and pre-operative assessment

Poor prognosis/decayed deciduous teeth added to plan

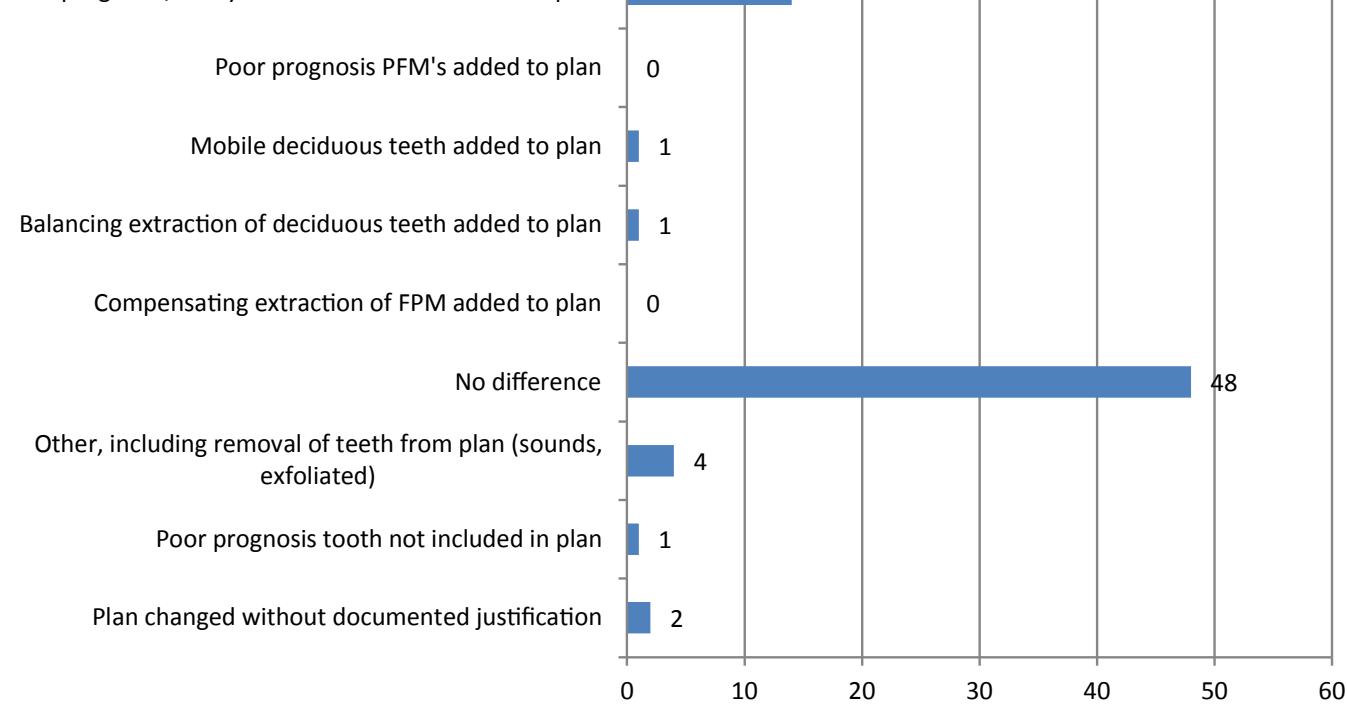

Figure 4: Distribution of the differences between the initial exam and the pre-operative assessment (number of patients out of 71) 
- For $67.6 \%(48 / 71)$ of patients there was no difference between the plan at the exam and POA.

- $22.5 \%(16 / 71)$ of patients had additional deciduous teeth added to the extraction plan.

- For 1 patient a carious deciduous tooth was not included in the plan.

- 2 patients had a change in the plan with no documented justification for the change.

\section{Differences between the Pre-operative Assessment Plan and GA}

Figure 5 below shows the differences between the POA and GA:

- $57.7 \%$ (41/71) patients had the same treatment at GA as the POA

- $7 \%(5 / 71)$ patients had fewer teeth extracted due to signs of very early decay or natural exfoliation

- Additional deciduous extractions were carried out under GA in $26.8(19 / 71)$ patients.

- 1/71 patient had a change in the plan without documentation.

- The previous issue in cycle 1 of notes not being available has resolved as we now scan the op notes onto R4.

\section{Patients Who were Caries Free at the Completion of GA}

$67 / 71$ patients $(94.3 \%)$ were caries free following completion of GA. According to the clinical records, four patients (may have) been left with decay as follows:

1. FPM's noted as being carious at GA. The patient was then rebooked for these teeth to be restored with preventive resin restorations after GA.

2. It appears that the GA clinician had charted UR5 as extracted at GA on R4 instead of URE in error. Therefore, on the chart carious URE is still present.
3. The LLD was documented as carious prior to GA, but was not added to the POA extraction plan and was also not extracted at GA. There was no mention in the operation notes about it and LLD is still charted as carious and present on R4.

4. URE was charted as a retained root in the R4 records, no mention of it at GA if it is present or missing. It is still charted as present on $\mathrm{R} 4$ after the GA.

\section{Post-GA Plan and Review}

\section{Justification for CDS Review}

3 patients with additional special care needs were discharged following GA. For 1 of these patients the POA stated to review after GA, but the patients was discharged with no additional justification (Table 7).

1 patient was reviewed due to decay being present at the end of $\mathrm{GA}$, which then required further restoration appointments.

Several patients with high numbers of teeth extracted at GA were not reviewed, for example, one patient had 18 deciduous extractions and was discharged.

1 patient was scheduled for review after GA in the operation note. No reason was given for why the review was needed. Nothing was ever booked in and the patient is still not discharged.

\section{Conclusion}

\section{Pre-Assessment}

- C1 100\% (79/79) of patients underwent a dedicated preoperative treatment planning session. This compared to $98.6 \%$ (70/71) for $\mathrm{C} 2$ as a patient had the initial assessment combined with the POA.

- The percentage of patients with a dedicated oral health appointment rose from $13.9 \%(11 / 79)$ for $\mathrm{C} 1$ to $38.0 \%(27 / 71)$ for $\mathrm{C} 2$ which is a $24.1 \%$ improvement.

\section{Difference between pre-operative assessment and GA}

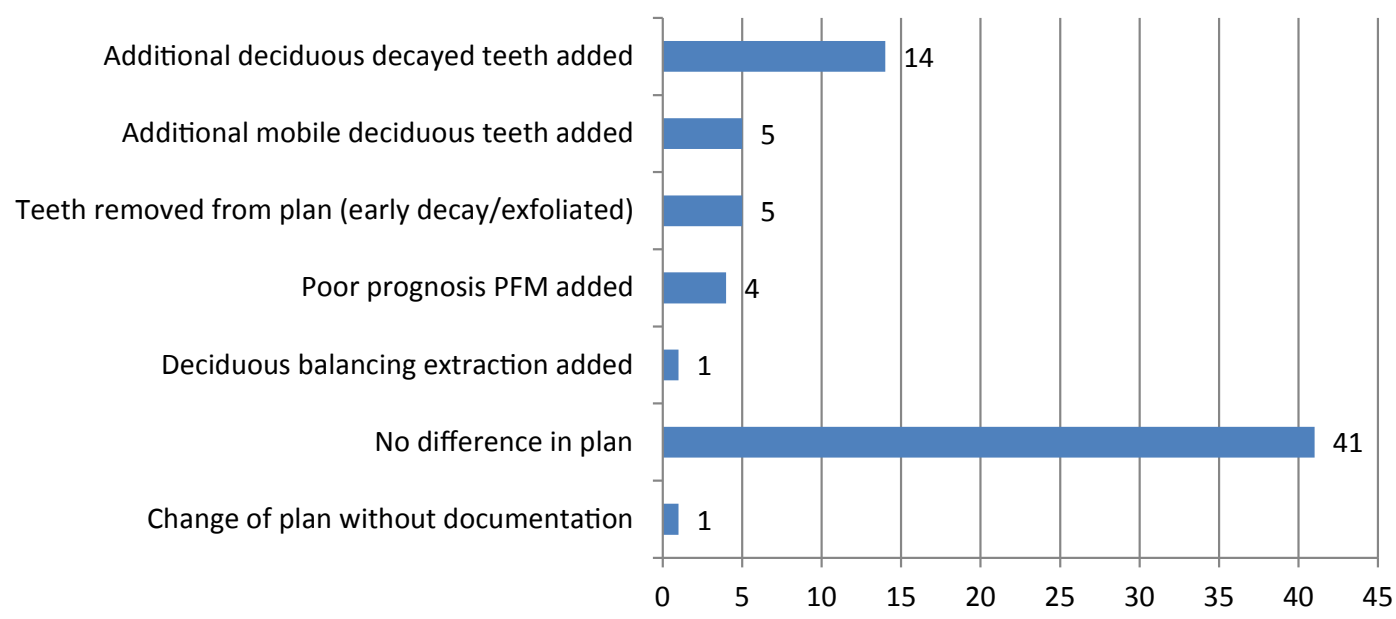

Figure 5: Distribution of the differences between the pre-operative assessment and treatment carried out at GA (number of patients out of 71). 


\section{Justification for GA}

- 1 patient had no documented justification for GA in their records for cycle 1 compared to 2 patients for C2. The target for documented justification of GA is $100 \%$.

\section{Pre-operative Radiographs for Deciduous Extractions}

- C1: $63.0 \%$ of patients (34/54) undergoing deciduous dental extractions did not have pre-operative radiographs compared to $64.7 \%(33 / 51)$ for $\mathrm{C} 2$

- For C1 26.5\% (9/34) did not have any documented for reason for radiographs not being taken compared to $9.1 \%$ (3/33) for C2. This shows a $17.4 \%$ improvement.

\section{Pre-operative Radiographs for Permanent Extractions}

- $100 \%$ of patients in C1 and C2 who were due for planned FPM extraction had pre-operative $\mathrm{x}$-rays.

- $88.5 \%(23 / 26)$ had the recommended OPG for C1 compared to $95.8 \%$ (23/24) for C2. This shows a $7.3 \%$ improvement.

\section{Balancing Extractions of Deciduous Canines}

- $\mathrm{C} 1: 9$ patients presented with caries unilaterally in a deciduous canine. Balancing extraction of the contralateral deciduous canine was planned and carried out in 6/9 cases (66.7\%).

- $\quad$ C2: 13 patients presented with unilateral decay in a deciduous canine, and balancing extraction was carried out in $11 / 13$ of these cases (84.6\%).

- This shows an improvement of $17.9 \%$

\section{Balancing Extractions of First Primary Molars}

- For C1, 12.5\% (2/16) patients had an assessment of deciduous molar spacing compared to $7.1 \%$ (1/14) for C2.

- No patients in $\mathrm{C} 1$ or $\mathrm{C} 2$ had documented balancing extractions of first primary molars.

\section{First Permanent Molar Extractions}

- The percentage with balancing/compensating extractions was C1 29.2\% (7/24) and C2 34.6\% (9/26)

- The percentage of patients who were advised of the risk of future mesial tipping or malocclusion of the second permanent molars rose from $8.3 \%(2 / 24)$ in $\mathrm{C} 1$ to $57.7 \%(15 / 26)$ in $\mathrm{C} 2$. This is a $49.4 \%$ improvement.
- 16/24 patients underwent timed elective extraction of poor prognosis first permanent molars in C1 compared to $12 / 26$ for $\mathrm{C} 2$.

- The patients who underwent assessment of skeletal classification dropped from $37.5 \%(9 / 24)$ in $\mathrm{C} 1$ to $30.8 \%$ $(8 / 26)$ for C2. This is a reduction of $6.7 \%$.

- Patients who underwent assessment of incisor classification rose from $58.3 \%(14 / 24)$ in $\mathrm{C} 1$ to $69.2 \%(18 / 26)$ for $\mathrm{C} 2$. This is a $10.9 \%$ improvement.

- Patients who underwent assessment of crowding rose from $16.7 \%(4 / 24)$ in $\mathrm{C} 1$ to $88.5 \%(23 / 26)$ for C2. This is a $71.8 \%$ improvement (Table 5).

\section{Differences between Initial Exam and GA Pre-operative} Assessment

- C1 $60.0 \%$ of patients (45/79) had the same number of teeth planned for extraction in the initial charting compared to the POA, compared to $67.6 \%$ (48/71) for C2

- For both C1 and C2, 1 patient had a carious deciduous tooth noted at the initial exam which was not included in the POA plan.

- For both $\mathrm{C} 1$ and C2, 2 patients had a change in the plan with no documented justification for the change.

\section{Differences between the Pre-operative Assessment Plan and} GA

- C1 $70.9 \%$ of patients (56/79) had the same number of teeth planned for extraction at the POA compared to GA, compared to $57.7 \%(41 / 71)$ for $\mathrm{C} 2$

- C1 $5.1 \%$ of patients (4/79) had a change in the GA plan without documentation. This compares to $1.4 \%(1 / 71)$ for $\mathrm{C} 2$.

\section{Patient Who were Caries Free at the Completion of GA}

- C1 no patients had outstanding restorative treatment to be carried out by the end of the GA session. C2 one patient had outstanding restorative treatment at the end of GA and subsequently had the upper 6's restored after GA.

- C1 78/79 patients (98.7\%) were caries free following completion of the GA session. According to the clinical chart, a carious deciduous incisor was still retained following treatment under GA.

Table 5: Information relating to first permanent molar extractions.

\begin{tabular}{|l|c|}
\hline Extraction of poor prognosis first permanent molars & No. of patients \\
\hline Pre-operative OPG radiograph & $23(88.5 \%)$ \\
\hline Balancing or compensating extractions performed & $9(34.6 \%)$ \\
\hline Balancing or compensating extractions not performed despite meeting criteria & $5(19.2 \%)$ \\
\hline Future risk of 7's tipping mesially or future malocclusion discussed & $15(57.7 \%)$ \\
\hline Total number of patients that had FPM extraction & 26 \\
\hline
\end{tabular}


- C2 67/71 patients (94.3\%) were caries free following the completion of GA. Some of these patients left with decay at the end of C2 may be attributed to record keeping errors.

\section{Post-GA Plan and Review}

- C2, 3 patients with additional special care needs were discharged following GA. For one of these patients the POA stated to review after GA, but the patients was discharged with no additional justification.

- Several patients with high numbers of teeth extracted at GA were not reviewed, for example, for C2, 1 patient had 18 deciduous extractions and was discharged (Table 6).

\section{Significance of Improvements and Compliance with Targets}

The most significant improvements have been made with the number of patients advised of the risk of future tipping/malocclusion of the second permanent molars after extraction of FPM (49.4\%).
Also with the patients who underwent assessment of crowding prior to permanent molar extraction ( $71.8 \%$ improvement).

\section{Discussion and Areas for Improvement}

- There is little consistency with whether patients have a dedicated oral health appointment prior to GA. For both cycles the vast majority of patients having these dedicated appointments are from Oldham compared to other boroughs.

- The justifications recorded for GA aren't always accurate. For example, some patients were listed as "pre-compliant" when in fact the patients had failed previous treatment attempts under inhalation sedation or local anaesthetic.

- Listing patients as being "pre-compliant due to age" seems subjective as each clinician appears to interpret this age limit differently. The same appears to stand for patients listed for "high number of extractions".

Table 6: Post GA plans for all of the patients.

\begin{tabular}{|l|c|}
\hline Post GA discharge/review plan & No. of patients \\
\hline Discharged as per plan & $59(83.1 \%)$ \\
\hline Reviewed with our service & $8(11.3 \%)$ \\
\hline Pending review & $4(5.6 \%)$ \\
\hline Post GA/review plan not documented and not discharged & 0 \\
\hline Total number of patients & 71 \\
\hline
\end{tabular}

Table 7: Justifications for why patients were reviewed with CDS rather than being discharged.

\begin{tabular}{|l|c|}
\hline Justification for CDS review & No. of patients \\
\hline Medical factors e.g. special care & $6(50 \%)$ \\
\hline Social factors e.g. looked after child & $2(16.7 \%)$ \\
\hline No general dentist & 0 \\
\hline $\begin{array}{l}\text { Other (high anxiety, previous XGA, poor attendance, poor compliance with OH, high number of teeth extracted } \\
\text { at GA/high dental needs, no justification) }\end{array}$ & $4(33.3)$ \\
\hline Total number of patients & 12 \\
\hline
\end{tabular}

Table 7.1 Significance of Improvements and compliance with targets

\begin{tabular}{|c|c|c|}
\hline Improvement & \begin{tabular}{|c|} 
Cycle 2 \\
Compliance
\end{tabular} & Target \\
\hline $\begin{array}{l}\text { There has been a notable improvement }(24.1 \%) \text { in the number of patients with a dedicated oral health appointment prior to GA. However the } \\
\text { percentage of patients in the re-audit }(38.0 \%) \text { is still below the target of } 100 \% \text {. }\end{array}$ & $38.0 \%$ & $100 \%$ \\
\hline $\begin{array}{l}\text { A } 17.4 \% \text { improvement in clinicians documenting justifications for not taking radiographs is positive. There were still } 9.1 \% \text { of patients without a } \\
\text { documented justification for no } \mathrm{x} \text {-rays, whereas there should ideally be } 0 \text { patients like this. }\end{array}$ & $9.1 \%$ & $0 \%$ \\
\hline $\begin{array}{l}\text { There was a } 7.3 \% \text { improvement in the number of patients with pre-operative OPG radiographs prior to permanent extractions. The target for } \\
\text { this is } 100 \% \text {, so the current compliance of } 95.8 \% \text { is good. }\end{array}$ & $95.8 \%$ & $100 \%$ \\
\hline $\begin{array}{l}\text { There was a } 17.9 \% \text { improvement in the number of patients having a balancing extraction of unilaterally carious deciduous canines. Current } \\
\text { compliance of } 84.6 \% \text { is significant and shows positive change, but the target for this is } 100 \% \text { (where justified) }\end{array}$ & $84.6 \%$ & $100 \%$ \\
\hline $\begin{array}{l}\text { All patients ( } 100 \% \text { ) having extraction of a unilaterally carious primary first molar should ideally have an assessment of spacing to inform whether } \\
\text { a balancing extraction is required. There was a reduction in compliance of } 5.4 \% \text { in the re-audit (overall } 7.1 \% \text { had an assessment of spacing) }\end{array}$ & $7.1 \%$ & $100 \%$ \\
\hline $\begin{array}{l}\text { The percentage of patients who were advised of the risk of future mesial tipping or malocclusion of the second permanent molars after extraction } \\
\text { of FPM improved by } 49.4 \% \text {. }\end{array}$ & $57.7 \%$ & $100 \%$ \\
\hline The patients who underwent assessment of skeletal classification prior to permanent molar extraction showed a reduction in compliance of $6.7 \%$. & $30.8 \%$ & $100 \%$ \\
\hline Patients who underwent assessment of incisor classification prior to permanent molar extraction improved by $10.9 \%$. & $69.2 \%$ & $100 \%$ \\
\hline Patients who underwent assessment of crowding prior to permanent molar extraction improved by $71.8 \%$. & $88.5 \%$ & $100 \%$ \\
\hline There was a 3.7\% improvement in C2 regarding the number of patients with changes to their GA plan without documentation compared to C1. & $1.4 \%$ & $0 \%$ \\
\hline
\end{tabular}


- There also seems to be no consistency with when clinicians try sedation first or when they send the patient for GA directly. This will obviously depend upon the clinician's assessment of compliance.

- Lower than expected numbers of patients with pre-operative radiographs may likely relate to compliance issues based on the justifications for patients listed for GA.

- In order to comply with guidance it is important for clinicians to justify not taking radiographs correctly rather than statements such as "not needed" without further explanation. To avoid unnecessary radiographic exposure it is also important for clinicians to be aware of when images are not required such as when all deciduous molars as clinically carious.

- Early loss of one deciduous canine is highly likely to lead to a centre line shift in the absence of spacing. Therefore it is positive to see an increase in the percentage of patients having appropriate balancing extractions in these cases. However, there appears to be little to no documentation of clinicians assessing first deciduous molars for balancing extractions (which is recommended in guidelines).

- The findings show that not all patients having extraction of FPM's are having the recommended pre-operative assessments. However, improvements have been made such as the number of patients having appropriate balancing/ compensating extractions and the percentage of patients advised of the risk of future malocclusion or of the second permanent molars tipping mesially. There was also an improvement in the percentage of patients who underwent incisal classification and an assessment of crowding. These improvements will help patients to avoid future orthodontic complications or avoidable orthodontic treatment.

- There may be a need for an x-ray facility at GA for all cases and not just special care cases. This will be helpful for routine exodontia cases where additional decay is found which may include permanent teeth.

- Patients should be caries free at the completion of GA. To a certain extent the discrepancies here seem more likely to be record keeping errors.

- A patient had their lower FPM's extracted at GA as per advice from their Paediatric Specialist Dentist. The specialist letter didn't mention compensating extractions so the clinician did not compensate the lower molar extractions with the upper molars or document an assessment of this. It is useful to still document orthodontic assessments in such instances.

- The issue from Cycle 1 has been overcome whereby records from Alder Hey Children's Hospital were not available locally as we are now scanning the op-note to R4 software postoperatively.

- Several patients with high numbers of teeth extracted at GA or high needs were not reviewed, while others were. We may benefit from a set protocol to improve consistency with this.
- It may also be beneficial to have a more robust follow-up system after GA. For example, a patient was planned for review after GA in their operation note. A recall was not set and the patient was still not discharged.

- A greater awareness of the Paediatric Exodontia guidelines amongst clinicians would be helpful. This should also help with pre-operative assessments and record keeping omissions/errors such as clinicians interchanging the terms "compensating" and "balancing" extractions, when these are in fact separate treatments.

- The number of patients pending review after GA for cycle 2 is impacted by the Covid-19 pandemic.

\section{Dissemination and Action Plan}

This audit highlights certain areas for further improvement. The following recommendations have been made:

1. Present findings locally to the dental directorate for example local clinical governance/audit meeting and local forums.

2. Present the findings for the research and clinical audit group meeting for the Trust and other interested parties.

3. Complete a re-audit when GA services resume subject to the Covid-19 pandemic.

4. Aim to publish the report in a peer reviewed journal, or a poster/oral presentation at a relevant dental conference as appropriate.

All of the following assume there has been thorough discussion of the risks and benefits of each point with documentation in the clinical notes should be clearly recorded with the reasons why:

1. If possible, bilateral dental bitewing radiographs are performed prior to the General Anaesthetic; unless caries is well established and frank in all Ds and Es, and all Ds and Es are planned for extraction.

2. If possible, upper anterior occlusal or periapical radiographs are performed for anterior teeth where there is a history of trauma, or caries into dentine in permanent teeth.

3. When first permanent molars are to be extracted, a DPT is necessary.

4. All children must be offered and attend a specific Oral Health appointment, with either a nurse with additional training (Oral Health Certificate) or a Dental Hygienist/Therapist. This is to discuss diet and toothbrushing prior to the GA.

5. Cs and Ds are balanced for orthodontic purposes (BSPD 2002). In a spaced arch, Ds should not be balance (RCS 2006).

6. Any deciduous tooth that has a poor long-term prognosis, or has been temporarily dressed with a temporary filling material, such as Glass Ionomer Cement, should be extracted at the GA appointment. Prioritise saving Es when possible for orthodontic benefit, extracting Ds can help maintain Es, as it removes the contact point (Consultant opinion, BDA CDS Group). 
7. Any deciduous tooth with two-surface caries/two-surface restoration, must be extracted at the GA appointment, as they pose a high risk for future problems.

8. Any tooth that is developmentally close to exfoliation, and has a poor prognosis (two-surface caries/two-surface restoration/ pulp treatment/mobile), should be extracted.

9. Any tooth that is very mobile, should be extracted.

10. Only strategic teeth (Es) with a very good prognosis, or evidence of missing permanent teeth, could be retained. For example, mildly affected hypoplastic Es with adequate composite sealants/restorations or a well-fitting stainless-steel crown, with radiographic evidence of no pathology; or perhaps in a child with missing second premolars, the Es can be considered to be retained after a GA if they have a good long-term prognosis.

11. If appropriate, an orthodontic opinion should be sought when considering extracting first permanent molars of poor prognosis.

a. Optimum time approximately 9 years of age

b. Where a maxillary first permanent molar is planned to be extracted, do not balance with one from the contralateral side.

c. Where a mandibular first permanent molar is planned to be extracted, do not balance with one from the contralateral side, but do consider a compensating extraction of the opposing maxillary first permanent molar.

d. Where both mandibular molars are to be extracted, consider extracting all four first permanent molars.

e. Where contralateral first permanent molars (e.g. upper right \& lower left) are to be extracted, consider extraction of all four first permanent molars.

f. In the majority of cases of Class I Incisors, if radiographic examination shows the furcations of the mandibular second permanent molars to be developing, and all four second permanent molars are present, and the mandibular first permanent molars are to be extracted, the maxillary first permanent molars should also be extracted (RCS 2004).

12. Children should not be offered GA for orthodontic extractions.

13. Any caries in deciduous teeth that is planned to be restored, must be restored prior to the GA appointment, and only if the clinical justification is strong. For example, minimal buccal cavities on maxillary Cs restored with composite or early minimal caries/mildly hypoplastic Es restored with composite or a well-fitting stainless-steel crown.

14. Any caries in permanent teeth planned to be restored, must be restored before the GA appointment. Co-operation cannot be presumed afterwards. Restorations under GA must be the exception (for children with special needs). When carrying out restorations under GA, consent must be sought for the restoration and for all possible extractions if the tooth has deep caries and a poor prognosis.
15. The child must be dentally fit after the GA appointment and must not wake up from a dental GA with caries.

16. Any child posing additional medical/social concern (e.g. no GDP, siblings have had dental GA, low income family, poor attendance, poor compliance with prevention advice, LAC, special needs, high number of teeth removed) should be followed-up within the CDS and guided to find a GDP on an individual basis. The person holding Parental Responsibility. If a guideline is not to be followed.

\section{References}

1. Extraction of Primary Teeth - Balance and Compensation (2002) British Society of Paediatric Dentistry.

2. Consultant Opinion "BDA London, CDS Group, March 2015. Dr Mike Harrison, Consultant in Paediatric Dentistry".

3. A Guideline for first permanent molar extraction in children (2004). Royal College of Surgeons. Williams A, McMullen R.

4. Extraction of Primary Teeth, Balance and Compensation (2006) by hospi College of Surgeons Faculty Working Party.

\section{Citation:}

Zaman I (2021) Treatment Planning for Paediatric Exodontia under General Anaesthesia: A Re-Audit. J Dent Maxillofacial Res Volume 4(2): 1-11. 
Appendix 1: Data collection proforma (PAGE 1)

\begin{tabular}{|c|c|c|c|c|c|c|c|c|c|c|c|c|c|c|}
\hline $\begin{array}{l}\text { R4 } \\
\text { No }\end{array}$ & Site & $\begin{array}{l}\text { Special } \\
\text { Care } \\
\text { patient? }\end{array}$ & Sex & Age & POA? & $\begin{array}{l}\text { POA } \\
\text { Date }\end{array}$ & $\begin{array}{l}\text { GA } \\
\text { Date }\end{array}$ & $\begin{array}{l}\text { Justification of GA } \\
\text { A) pre cooperative due to } \\
\text { age } \\
\text { B) Failed Treatment under } \\
\text { IHS/LA } \\
\text { C) Multi quadrant XLA } \\
\text { D) No reason given } \\
\text { E) Lack coop special care } \\
\text { Justification of GA } \\
\text { F) Lack cooperation }\end{array}$ & Radiographs & $\begin{array}{l}\text { Why no Radiographs? } \\
\text { A) Lack coop } \\
\text { B) Attempted, not } \\
\text { tolerated } \\
\text { C) All deciduous molars } \\
\text { clinically carious } \\
\text { D) No Justification }\end{array}$ & \begin{tabular}{|l|} 
Initial/POA \\
plan \\
A) \\
Restoration \\
prior to GA \\
B) All carious \\
teeth to be \\
extracted \\
c) Restoration \\
under GA
\end{tabular} & $\begin{array}{l}\text { Canines to be } \\
\text { balanced? } \\
\text { IF YES: } \\
\text { A) planned } \\
\text { balancing } \\
\text { XGA C's } \\
\text { B) Bal } \\
\text { discussed, } \\
\text { declined by } \\
\text { parents } \\
\text { C) C's not } \\
\text { balanced, no } \\
\text { justification }\end{array}$ & $\begin{array}{l}\text { A) FPM for } \\
\text { XGA Yes/No } \\
\text { B) Timed/ } \\
\text { Not timed } \\
\text { XGA } \\
\text { (optimum } \\
\text { 9y) } \\
\text { or if L7's } \\
\text { furcation } \\
\text { developing } \\
\text { C) Bal/ } \\
\text { Comp? } \\
\text { D) risk of } \\
\text { 7's tipping } \\
\text { discussed }\end{array}$ & $\begin{array}{l}\text { Ortho } \\
\text { considerations } \\
\text { for planned } \\
\text { extractions of } \\
\text { FPMS } \\
\text { A) Assessment } \\
\text { skeletal } \\
\text { classification } \\
\text { Y/N } \\
\text { B) Assessment } \\
\text { crowding Y/N } \\
\text { C) Assessment } \\
\text { Angles } \\
\text { classification } \\
\text { Y/N } \\
\text { D) Referred for } \\
\text { orthodontic } \\
\text { advice Y/N }\end{array}$ \\
\hline
\end{tabular}

Appendix 1: Data collection proforma (PAGE 2)

\begin{tabular}{|c|c|c|c|c|c|c|c|}
\hline $\begin{array}{l}\text { E) Spacing checked } \\
\text { for deciduous teeth? } \\
\text { F) D's balanced if not } \\
\text { spaced? }\end{array}$ & $\begin{array}{l}\text { Exam vs. POA plan } \\
\text { A) Additional decayed teeth } \\
\text { added } \\
\text { B) Additional mobile teeth } \\
\text { added } \\
\text { C) Teeth removed from plan } \\
\text { D) No difference } \\
\text { E) no record of why plan } \\
\text { changed } \\
\text { F) additional balancing } \\
\text { compensating XLA added } \\
\text { G) missed decayed tooth }\end{array}$ & $\begin{array}{l}\text { POA plan v GA plan } \\
\text { A) Additional decayed teeth added } \\
\text { (deciduous) } \\
\text { B) Additional mobile teeth added } \\
\text { (deciduous) } \\
\text { C) Teeth removed from plan (early } \\
\text { decay/exfoliated) } \\
\text { D) No difference } \\
\text { E) poor prognosis FPM added } \\
\text { F) Balancing XLA added } \\
\text { (deciduous) } \\
\text { G) Comp added perm } \\
\text { H) No record }\end{array}$ & $\begin{array}{l}\text { Caries Status } \\
\text { after GA } \\
\text { F) Caries Free } \\
\text { C) Caries } \\
\text { Present }\end{array}$ & $\begin{array}{l}\text { Review status } \\
\text { A) discharged as per plan } \\
\text { B) reviewed } \\
\text { C) Not documented } \\
\text { D) for review, not booked }\end{array}$ & $\begin{array}{l}\text { Reason for review } \\
\text { A) no GDP } \\
\text { B) previous XGA } \\
\text { C) poor attendance } \\
\text { D) poor compliance } \\
\text { with OH } \\
\text { E) LAC } \\
\text { F) Special Care } \\
\text { G) high no of teeth } \\
\text { XGA } \\
\text { H) anxious } \\
\text { I) Social issues }\end{array}$ & $\begin{array}{l}\text { Dedicated } \mathrm{OH} \\
\text { Apt? }\end{array}$ & $\begin{array}{l}\text { Restorations prior to GA } \\
\text { for teeth to be retained? }\end{array}$ \\
\hline
\end{tabular}

